\title{
Synthesis of PTFE based Air Cathode for Metal Air Battery
}

\author{
Sangwon Seo ${ }^{1,2}$, Kwangyeop Jang ${ }^{3}$, Jongwoo Park ${ }^{1,2}$ and Dongjin Kim ${ }^{\mathrm{a}}$ \\ ${ }^{1}$ SUNKWANG L.T.I. INC., Central Research Institute of Technology, Seoul, Republic of Korea \\ ${ }^{2}$ SUNKWANG L.T.I. INC., Institute of Field Research Center, Seoul, Republic of Korea \\ ${ }^{3}$ Korea Conformity Laboratories, Parts and Materials Headquarters, Seoul, Republic of Korea \\ ${ }^{a}$ SUNKWANG L.T.I. INC., Head-Quarter, Seoul, Republic of Korea
}

\begin{abstract}
A large number of researchers devotes deep study to reducing the contact resistance and improving the durability of air cathode. Air cathode consists of gas diffusion layer, current collector and catalytic layers. The network structure (gas diffusion layer, GDL) of Air cathode plays an important role in metal-air battery. This GDL makes the air-cathode semi-permiable. It means that $\mathrm{H}_{2} \mathrm{O}$ does not pass through GDL layer but $\mathrm{O}_{2}$ moleecules can pass the layer. For that reason, the optimization of sintering condition is very important process in manufacturing Air cathode. This article is about the dependence of discharge property of magnesium air-battery to its sinter-ability. Thus in order to observe any changes in the discharge property, sinter-ability, a cost-effective method was designed in the air cathode production.
\end{abstract}

\section{Introduction}

Energy is a necessity in modern civilization. Unfortunately, energy of various forms is primarily generated from fossil fuels, which cause serious air pollution and are limited in availability. Therefore, in the age where the development of new forms of clean energy is urgent, metal-air electrochemistry emerged not only as a novel battery candidate, but also as a replacement to fossil fuel-based energy production due to its high specific energy[1-4].

And it is also true that interest in eco-friendly energy has grown, and that interest in batteries has grown very much. Especially among the many battery candidates, the research and industry on lithium ion batteries are the most active. However, because of the toxicity of electrolytes in lithium-ion batteries, the price problems of lithium, a rare earth, and the explosion issues of lithium-ion batteries, the worst drawback of it, metal air cells are emerging as alternatives to Li-ion batteries.

Amongst the various metal-air batteries, magnesiumair battery is considered one of the most environmentfriendly for it can use salt water as an electrolyte and forms a valuable by-product, magnesium hydroxide. Magnesium also has other advantages, such as low density, high chemical reactivity, high theoretical specific energy and high theoretical energy density $\left(3.8 \mathrm{Ah} / \mathrm{cm}^{3}\right)$. Besides, magnesium is also the one of the most abundant metals on the Earth. Despite these benefits of magnesium, however, there is a need to overcome many barriers to the battery development such as the improvement of corrosion, discharge property and etc[5-8].

One of the major obstacles of Mg-air battery, compared to other types of batteries, is the relatively low output voltage per unit volume. As part of a study to minimize the disadvantages and optimize the said battery above, this paper investigates how the change in discharge properties and the change in the sinter-ability among the different dwelling temperature[9-11].

\section{Experimental Procedure}

\subsection{Material}

Starting materials were Activated Carbon powder(AC, BET 1,350-1,650, Power Carbon Technology) and Cobalt(II,III) oxide powder(black 70\%, Daejung chemical, South Korea). The AC and cobalt oxide were mixed in Ethanol. The mixed slurry was ultra sonicated for dispersion. PolyTetraFluoroEthylene preparation (PTFE, $60 \mathrm{wt} \%$ dispersion in $\mathrm{H}_{2} \mathrm{O}$, Sigma Aldritch) was added to the mixed slurry dropwise during the ultrasonication. The $\mathrm{AC}-\mathrm{Co}_{3} \mathrm{O}_{4}$-PTFE-Ethanol mixture (wt. ratio $4: 2: 6$ ) was heated at $80^{\circ} \mathrm{C}$ while stirring at $300 \mathrm{rpm}$ until the mixture became a dough-like paste.

Nickel foam (purity: $99.5 \%$, density: $350 \mathrm{~g} / \mathrm{m}^{3}$, thickness: $1.6 \mathrm{~mm}$, Invisible Inc.), a current collector, and dough-like powder-PTFE mixture were each rolled into $0.3 \mathrm{~mm}$ sheets. Then, the two sheets were rolled together. After rolling, the rolled sheets were pressed uni-axially with various pressure ( 3 ton, 10 ton, and 20 ton).

\subsection{Sintering}

The pressed sheet was sintered in the furnace at $360^{\circ} \mathrm{C}$ for $30 \mathrm{~min}$. Heating rate was $30^{\circ} \mathrm{C} / \mathrm{min}$ (Fig.1).

\footnotetext{
a Corresponding author: isk0910@hanmail.net
} 


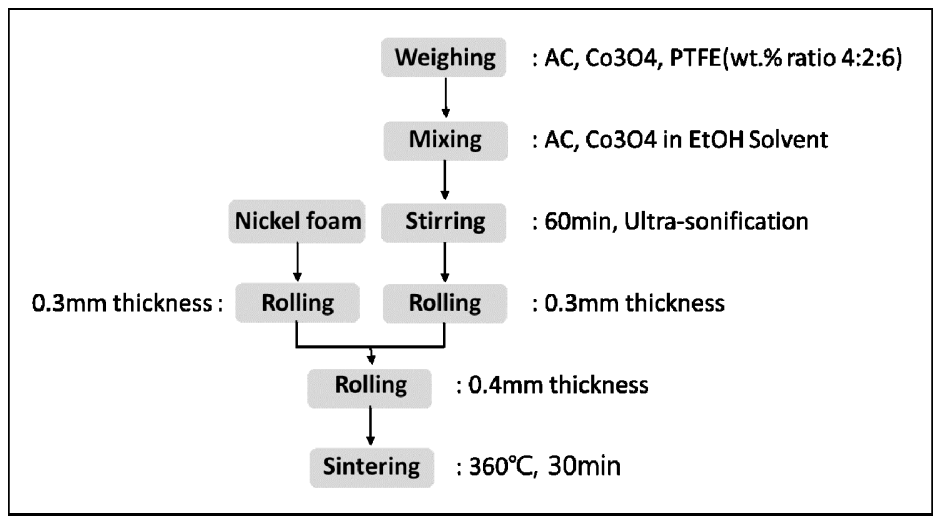

Figure 1. Schematic diagram of experimental procedure.

\subsection{Analysis}

structure of the cathode was analysed via optical

The electrical property of the air-cathode was measured by DC electronic Load (M9175B, Maynuo). The micro-

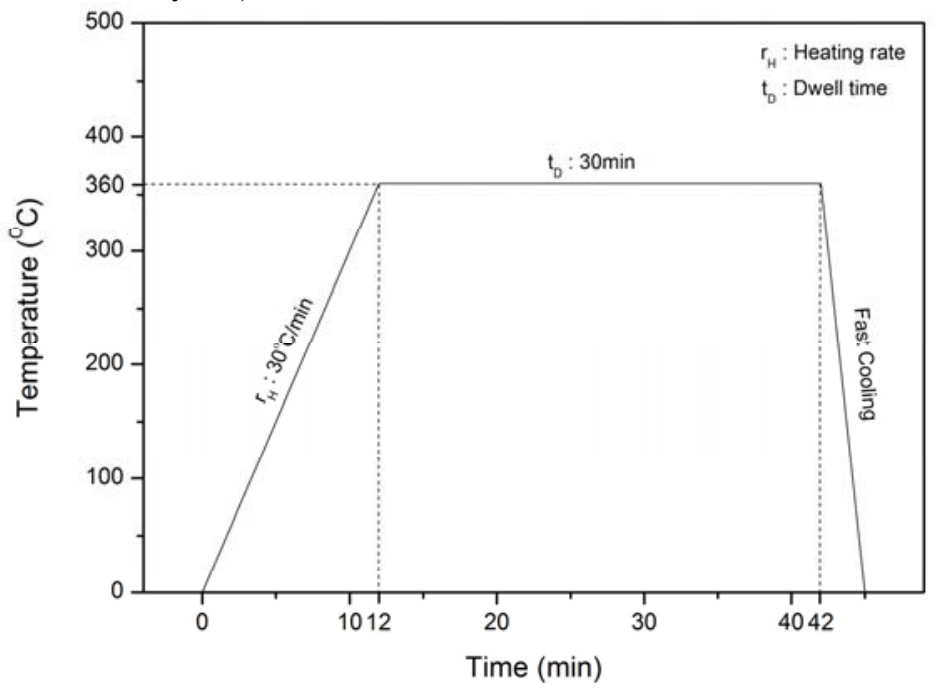

Figure 2. Sintering schedule.

\section{Result and Discussion}

\subsection{Sintering Schedule Optimization}

To optimize sintering schedule, various dwelling temperature from $270{ }^{\circ} \mathrm{C}$ to $360{ }^{\circ} \mathrm{C}$ was applied. Because of the melting temperature of PTFE is $327{ }^{\circ} \mathrm{C}$, this temperature range was chosen. There was honeycomb network structure in the sample which is sintered at the temperature $360{ }^{\circ} \mathrm{C}$ (Fig. 5, Fig. 6). This network structure makes the air cathode semi-permeable layer. That is, water can't pass through the air cathode but oxygen molecules can pass because of this network structure. Although $330^{\circ} \mathrm{C}$ is higher than the melting temperature of PTFE, there was no the network structure (Fig.3, Fig.4).

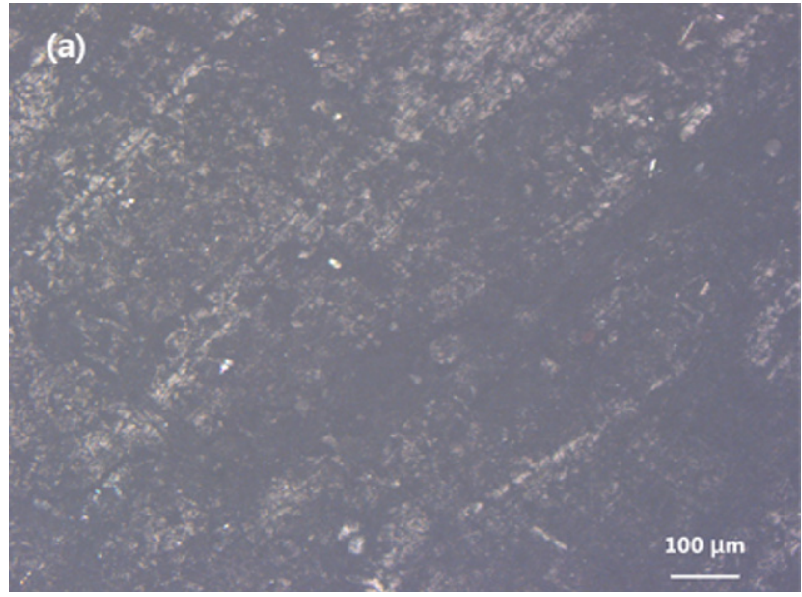

Figure 3. Optical microscope images of sintered sample. (Condition of (a) : $330{ }^{\circ} \mathrm{C}, 0.5 \mathrm{~h}$, Magnification : 200) 


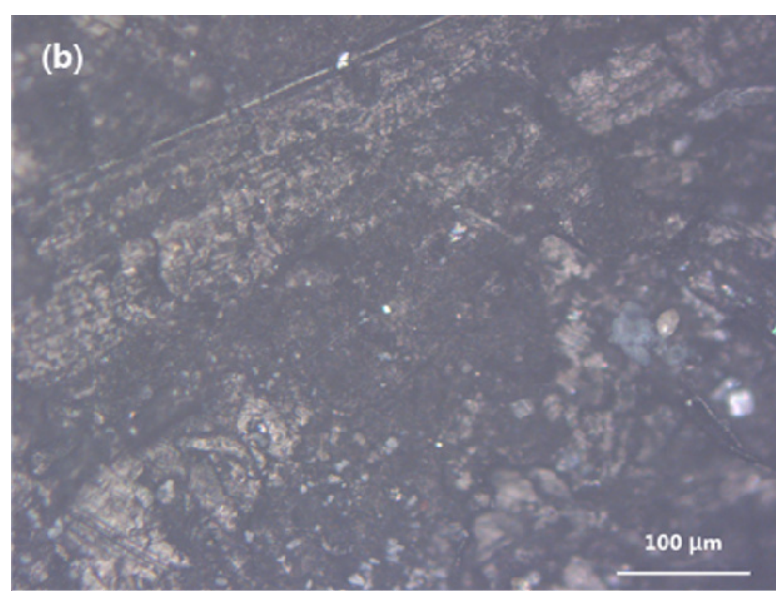

Figure 4. Optical microscope images of sintered sample. ( Condition of (b) : $330^{\circ} \mathrm{C}, 0.5 \mathrm{~h}$, Magnification : 500)

\subsection{Property}

The graph below (Fig.4) depicts the Current vs. Voltage curve of five different samples. Although there are some differences in sintering methods between the reference cathodes and the sample cathodes (Companies A and B uses hot press, while our three samples were sintered at atmospheric pressure), the samples fabricated at 3 tons, 10 tons, and 20 tons of pressure were compared with the reference materials from companies A and B. 3 tons sample exhibited the lowest performance, where it could only produce $0.35 \mathrm{~V}$ at $2 \mathrm{~A}$ conditions. 20 tons sample, while not fabricated via the same hot-press method, displayed performance similar to, if not better than those of the reference cathodes. This data shows that the fabrication method of our group is more cost-effective and time-efficient.

The improvement in voltage output along with the increase in pressure of the fabrication conditions is inferred to be related to the decrease in the contact resistance. In other words, the pressure term is a crucial factor to the fabrication process of our group. Nevertheless, the pressure term has not been optimized, and thus is subject to further studies.

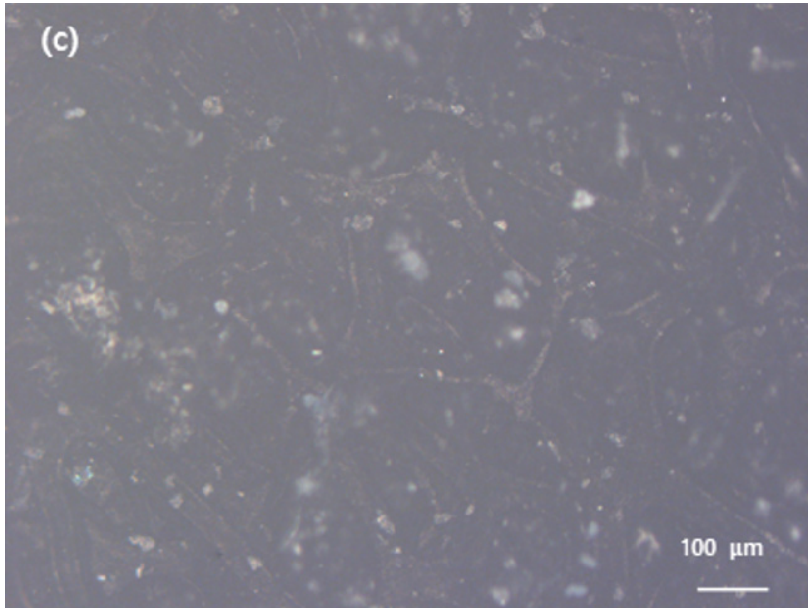

Figure 5. Optical microscope images of sintered sample. (Condition of (c) : $360^{\circ} \mathrm{C}, 0.5 \mathrm{~h}$, Magnification : 200)

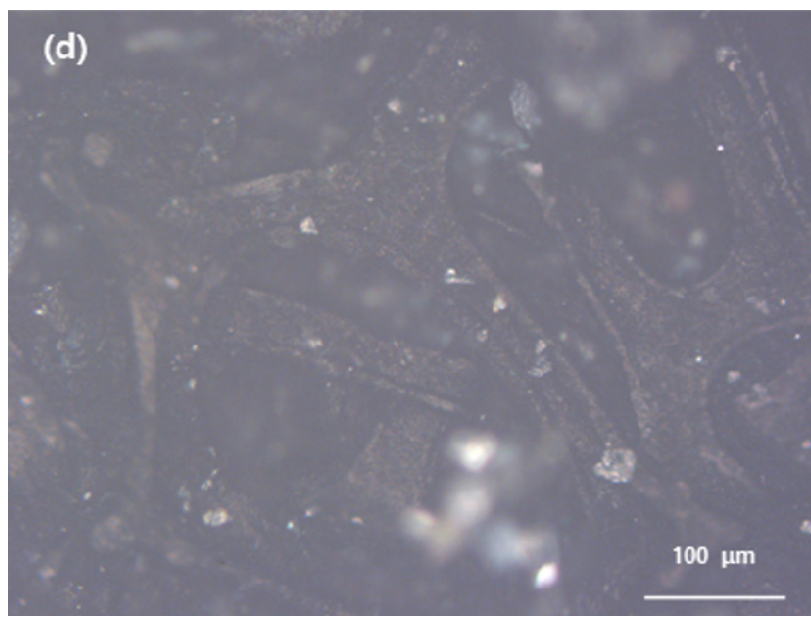

Figure 6. Optical microscope images of sintered sample. ( Condition of (d) : $360{ }^{\circ} \mathrm{C}, 0.5 \mathrm{~h}$, Magnification : 500)

\section{Conclusion}

1. Sintering temperature was optimized. Unless hot press isn't used, $360{ }^{\circ} \mathrm{C}$ optimal temperature.

2. Because the contact resistance is the most important component to fabricate this air-cathode, the pressure over 20 tons is needed.

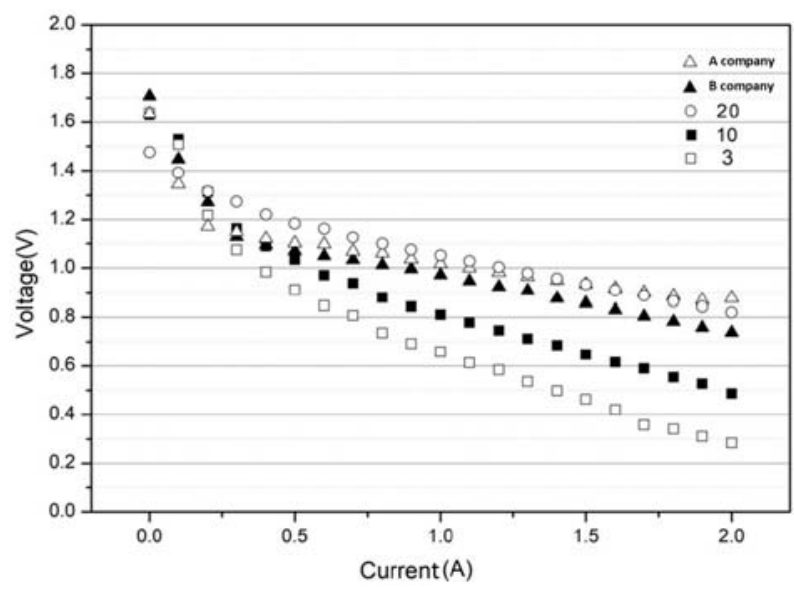

Figure 7. Current vs. Voltage curve of Air-cathodes 


\section{Acknowledgments}

This research was supported by the Technology Innovation Program (20001088, Development of environment friendly personal emobility products and experiential sharing platform service design based on tourismlesport) funded By the Ministry of Trade, industry \& Energy (MI, Korea)

\section{References}

1. Shuzhi Liu, et al., "Rechargeable Zinc Air Batteries and Highly Improved Performance through Potassium Hydroxide Addition to the Molten Carbonate Eutectic Electrolyte, J. Electrochem. Soc. 165 (2018) A149-A154.

2. Jing Fu, et al., "Electrically Rechargeable Zinc-Air Batteries: Progress, Challenges, and Perspectives, Adv. Mater., 2017, 29, 1604685.

3. Bruno Scrosati, Jurgen Garche, "Lithium batteries: Status, prospects and the future", J. Power Sources, 2010, 2419-2430. 336

4. F. Cheng, J. Chen, "Metal-air batteries: from oxygen reduction electrochemistry to cathode catalysts, Chem. Soc., pp.2172-2192, Jan, 2012

5. Md. Arafat Rahman, Xiaojian Wang, and Cuie Wen, "High Energy Density Metal-Air Batteries: A Review", J. Electrochem. Soc., 2013, A1759-A1771.

6. Y.D. Milusheva, R.I. Boukoureshtlieva, S.M. Hristov, A.R. Kaisheva, "Environmentally-clean Mg-air electrochemical power sources", Bulagarian Che. Com., Volume 43, pp.42-47, Sep, 2010

7. Y.D. Milusheva, R.I. Boukoureshtlieva, S.M. Hristov, A.R. Kaisheva, "Environmentally-clean Mg-air electrochemical power sources", Bulagarian Che. Com., Volume 43, pp.42-47, Sep, 2010.

8. B. Shaw, "corrosion resistance of magnesium alloys", ASM Handbook, 2003.

9. Martin Wolff, et al., "Sintering of Magnesium", Advanced Engineering Materials, 2010, 12.

10. J. Ma, J. Wen, J. Gao, Q. Li, "Performance of Al$1 \mathrm{Mg}-1 \mathrm{Zn}-0.1 \mathrm{Ga}-0.1 \mathrm{Sn}$ as anode for Al-air battery", Electrochim. Acta, pp.69-75, Feb, 2014.

11. S. Yang, H. Knickle, "Design and analysis of aluminum/air battery system for electric vehicles", J. Powder Sources, pp.162-173, Oct, 2002. 